\title{
The importance to discuss the regionalization process in health
}

The national health systems organization in regionalized formats acquired a major importance in many health systems and also became an inspiring design for the contemporary changes that have embraced the policy of decentralization guidelines. In addition, with greater or lesser emphasis, the theme has remained as the center of attention throughout the implementation course of the Sistema Único de Saúde (SUS) (Public Health System) in our country.

After 17 years of an emergency technical norm from the Ministry of Health - which indicated the constitution of health regions by the Federation States (Norma Operacional Básica 01 de 2000) (Basic Operational Norm 01 in 2000) and several federal normative to encourage the regionalization process and the network formations (Pacto pela Saúde de 2006; Decreto Lei 7508, de 2011 e o Decreto 4279 de 2010 que propugna a constituição das RAS) (Health Pact in 2006; Decree Law 7508 in 2011 and the Decree 4279 in 2010 which advocate the formation of RAS) - it is important to report how we have advanced in this process, thus, we can contribute with a more detailed debate on health regionalization.

Região e Redes (Region and Networks) research proposed to study and disseminate knowledge about the features on the regionalization process in Brazil, understanding as the process constitutes in the health regions. On the other hand, considering the hypothesis of the regional organization of services and the health actions, is an important tool for the universalization which will implicate the improvement of some indicators and, consequently, improve the performance in the health regions.

The reason for this assertive is to regulate and direct the flow of services and people within a delimited territory means in introducing improvements for the access of services and a more rational use of resources, assisting in an integral form for the health necessities.

It is not easy to discuss this issue, in addition to the characteristic study points of the healthcare in territories and the behavior flow of people between intra- and inter- health regions services, it is necessary to explain these movements in the function of also other variables that extrapolate and is not always evident the availability of services, or the availability of offering.

Regarding this, the field studies are necessary for the primary data survey, embracing innumerous aspects on policy, planning and health management. In other words, it is necessary to look for different dimensions and/or aspects that form the activity of satisfying the needs in health.

And for this purpose, the research was performed in the five health regions in five Brazilian macro-regions: Entorno Manaus and Alto Rio Negro in the North; Baixada Cuiabana in the Midwest; Petrolina and Juazeiro in the Northeast; North Barretos and South Barretos in the Southeast; Carbonífera and Costa Doce in the South.

These regions embrace by the division of the Urbano Regional do Instituto Brasileiro de Geografia e Estatística (IBGE), (Regional Urban Brazilian Institute of Geography and Statistics), a National metropolis, a regional capital and cities with different densities of urban networks and besides the State and International boundary areas, regions with different compositions of public and private services and belonging to different groups, according to the typology proposed by the research.

The same regions contemplate the population that varies from 384,175 to $2,119,145$ inhabitants, with varied demographic densities, populational growth rates and elderly populational rates, in addition to a regional performance that is non-homogeneous, according to the Indicador de Desempenho Regional (Regional Performance Indicator) created by this research.

The choice of these regions for the field study is exactly due to the variability present in the territories, which enables us to verify how this specific composition of features impacts the regionalization process and what particular aspects this has on others, such as the history in health policy in these same regions.

The research team, formed by researchers from different institutions, had chosen as priority study themes of the governance in the regionalization process, the primary care, the Rede de Urgência e Emergência (Urgency and Emergency Network) and the health surveillance.

As the tracers opted Cerebrovascular accident (CVA) for chronic diseases, dengue fever and tuberculosis by surveillance.

More than 30 therapeutic itineraries were conducted for CVA in these same areas in order to obtain an inte- 
grated view of the course of the patients and the health services.

A specific study was produced on medical mobility and organizational forms of providing medical services in the five regions by using secondary data and interviews conducted in the health regions.

Complementary studies were also performed on offerings and the characteristics of health-related training in these regions and its impact in the regionalization process, as well as on the scope of practice in primary health care.

A result of all of these activities was the creation of a wide database on these same regions (secondary and primary) collected through structured questionnaires (a total of 221), and innumerous interviews with previously prepared scripts.

An average of 25 researchers participated in each regional study, aided by researchers from collabora-ting institutions of the field: Fiocruz, in Manaus, Universidade Federal da Bahia and Instituto de Medicina Integral Prof. Fernando Figueira (IMIP) in Petrolina and Juazeiro; Universidade Federal do Mato Grosso in Baixada Cuiabana; and Universidade Federal do Rio Grande do Sul in Carbonífera and Costa Doce regions.

The methodological approach of this research relied on the identification of four dimensions that could explain the regionalization process:

It starts with the policy process itself, by identifying the performance spaces, negotiation and conflicts in the region, processes and decision-making flows and the conduct of policy. Besides, pointing out a panorama about the technological incorporation and the respective regional decisions, including the judicialization importance which is recent in these regions.

The structural is another dimension that translates the availability and adequacy of financial and physical human resources, the forms to employ human resources and services, monitoring and evaluation.

The organization dimension intends to identify the conformation criteria of the Rede de Atenção à Saúde (RAS) (Healthcare network), planning, management and the systemic integration among services, regulation and access.

Finally, the intersectoriality dimension that seeks evidence of the intersectoral actions present in the region. It is within each of these dimensions that we have discussed about primary care, the urgency and emergency network and the health surveillance. Hence, we may have for each level of care as an integrated view of the policy, the structural and the organizational.

We consider these different dimensions have, at the same time, different levels of autonomy and interdependence aspects. Only an integrated view on these dimensions were allowed to identify which problems were the most recurrent in each one of them separately, and in what form these dimensions may interfere, altogether, in the regionalization process.

The expression of this is the creation of a composed indicator that emphasizes the degree to implement the regionalization process and its most evident obstacles. We may see comparatively different realities and the interference of aspects relatively specific, such as the histories of local sanitaries are.

Given the scope and relevance of the theme addressed here to a wide evaluation, although, not exhaustive, the regionalization process of the health systems in Brazil, the Brazilian Journal of Mother and Child Health which includes in its scope studies on Public Health - could not leave these publications out of this issue.

This special issue for the Brazilian Journal of Mother and Child Health is composed of 11 original articles focused on the research aspect discussed in this editorial: an article that portrays the methodological choices and the comparison of regionalization indicator in these regions and demonstrates the construction of the attributions in the regionalization and its performance in different realities.

The articles here are based on the results of researches focused on primary care, medical mobility, health surveillance, flows of offerings and technological incorporation.

We hope that all this content provides the reader a review of the regionalization process and its current barriers, in addition to a rich methodological discussion on how to better evaluate this process.

Have a pleasant reading!

Ana Luiza d'Ávila Viana 1

Eronildo Felisberto 2

1 Departamento de Medicina Preventiva. Faculdade de Medicina. Universidade de São Paulo. São Paulo, SP, Brazil.

2 Instituto de Medicina Integral Prof. Fernando Figueira. Recife, PE, Brazil. 